\title{
Right anterior minithoracotomy aortic valve replacement with a sutureless bioprosthesis: Early outcomes and 1-year follow-up from 2 European centers
}

\author{
Marco Vola, MD, PhD, ${ }^{a}$ Alberto Albertini, MD, ${ }^{b}$ Salvatore Campisi, MD, ${ }^{a}$ Luca Caprili, MD, ${ }^{b}$ \\ Jean-François Fuzellier, MD, ${ }^{\mathrm{a}}$ Jean-Pierre Favre, MD, ${ }^{\mathrm{a}}$ Jérôme Morel, $\mathrm{MD},{ }^{\mathrm{c}}$ and Antoine Gerbay, $\mathrm{MD}^{\mathrm{d}}$
}

\begin{abstract}
Background: A sutureless aortic valve can be inserted through a right anterior minithoracotomy (RAMT) with consistent decreased cross-clamping time and ease of insertion. We report the experience of RAMT implantation of the $3 \mathrm{f}$ Enable (Medtronic, Inc, Minneapolis, Minn) self-expanding sutureless bioprosthesis, performed in 2 European cardiac surgery centers.
\end{abstract}

Method: From September 2012 to April 2014, a total of 71 patients with severe aortic stenosis were selected to receive an aortic valve replacement via RAMT using the sutureless valve. Hemodynamic parameters and clinical outcome were assessed at discharge and up to 16 months postoperatively.

Results: All the patients received the prosthesis with success. One conversion to median sternotomy was necessary, owing to severe pleural adhesions. Overall inhospital mortality was $2.8 \%$. Mean cardiopulmonary bypass and cross-clamping time were, respectively, $91 \pm 29$ minutes and $66 \pm 19$ minutes. Reclamping was necessary in 4 cases $(5.6 \%)$. Early incidences of grade I or lower paravalvular leakages and pacemaker implantation were, respectively, 4.2\% and 5.6\%. No paravalvular leakage greater than grade I was registered. The mean follow-up time was 8.1 months; the mean transvalvular gradient was, at discharge and at 6-12 months, respectively, $10.7 \pm 4.3 \mathrm{~mm} \mathrm{Hg}$ and $9.6 \pm 3.1 \mathrm{~mm} \mathrm{Hg}$. The degree of regurgitation remained stable in all cases. Freedom from all-cause and valverelated mortality was $97 \%$ and $99 \%$, respectively, at 1 year.

Conclusions: Aortic valve replacement via RAMT with the $3 \mathrm{f}$ Enable valve is a reproducible procedure, as it provides satisfactory hemodynamics, and a low valve-related complication rate. Greater experience is needed to compare the performance of the $3 \mathrm{f}$ Enable valve with that of other sutureless valves implanted via the same RAMT procedure. (J Thorac Cardiovasc Surg 2015;149:1052-7)

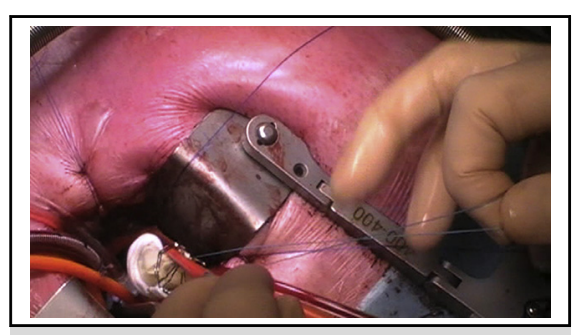

Folded 3F Enable prosthesis descended into the right anterior minithoracotomy.

\section{Central Message}

Sutureless 3f Enable aortic valve replacement is reproducible and safe, combining reasonable cross-clamping times and a low rate of paravalvular leakages. A learning curve in management of the step-by-step delivery of the sutureless prosthesis has to be acquired before proceeding to minithoracotomy.

\section{Perspective}

Reduction of cross-clamping time and enhancement of reproducibility of challenging minimally invasive approaches are pivotal indications in use of sutureless valves. This is the first multicentric cohort of right anterior minithoracotomy aortic valve replacements with use of the unique sutureless prosthesis, the $3 \mathrm{f}$ Enable valve, that is not balloon expandable and that needs a precise surgical positioning. Incidence of paravalvular leakages seems interestingly low, confirming that this setting may merit a larger diffusion as a first-line option for isolated minimally invasive aortic valve replacement.

See Editorial Commentary page 1058.
Results in favor of transcatheter valve implantation rather than surgical aortic valve replacement in high-risk patients have been published recently. ${ }^{1}$ Early results in

From the Cardiovascular Surgery Unit, ${ }^{\mathrm{a}}$ Cardiovascular Diseases Department University Hospital, St-Etienne, France; Cardiovascular Surgery Unit, ${ }^{\text {b }}$ Salus Hospital GVM Care \& Research, Reggio Emilia, Italy; Anesthesiology and Reanimation Department, ${ }^{\mathrm{c}}$ University Hospital, St-Etienne; and Cardiology Unit, ${ }^{\mathrm{d}}$ Cardiovascular Diseases Department, University Hospital, St-Etienne, France.

Received for publication Sept 17, 2014; revisions received Nov 12, 2014; accepted for publication Dec 11, 2014; available ahead of print Jan 31, 2015. new-generation transcatheter valve implantation ${ }^{2}$ will potentially stimulate the debate concerning surgical versus transcatheter options in intermediate-risk patients. On 


\section{Abbreviations and Acronyms \\ $\mathrm{CPB}=$ cardiopulmonary bypass \\ NYHA $=$ New York Heart Association \\ PVL = paravalvular leakage \\ RAMT $=$ right anterior minithoracotomy}

the other hand, persistence of the native valve after transcatheter valve implantation has raised concern regarding persistence of tissues that have potential to act as a nidus for calcified emboli, and altered rheology that promotes thrombosis. This issue is under investigation by Fanning and colleagues ${ }^{3}$ as one of the possible causes of neurologic injury that should be assessed before extension of transcatheter valve implantation into populations that are younger and have lower surgical risk. Surgery is the only solution that can remove the underlying pathology, and technical refinement of this procedure is still possible and necessary.

Considerable effort has been made to reduce the iatrogenic effects of surgical aortic valve replacement chest wall trauma. The challenge began with the assessment of ministernotomies, ${ }^{4,5}$ and these efforts could evolve into the exclusive thoracoscopic approach. ${ }^{6}$ In this stepwise evolution, right anterior minithoracotomy (RAMT) seems to be an adequate compromise, intended as a routine safe and reproducible approach that avoids partial fractures of the sternum ${ }^{7}$ and has already shown clinical advantages in term of transfusions, ventilation time, and reduction of postoperative atrial fibrillation onset. ${ }^{8,9}$

The introduction of sutureless technology, which avoids the use of stitches and knots, has the potential to increase the speed of insertion, regardless of the location of incision. Evaluation has been made ${ }^{10}$ of large cohorts of patients who have undergone implantation of the Perceval S sutureless bioprosthesis (Sorin Biomedica Cardio Srl, Saluggia, Italy) via RAMT, but to the best of our knowledge, no study has been published on a multicenter cohort for which the $3 \mathrm{f}$ Enable model 6000 valve (Medtronic, Inc, Minneapolis, Minn) was utilized. The aim of the current study is to analyze our clinical experience with RAMT using the $3 \mathrm{f}$ Enable.

\section{METHODS}

\section{Patient Population}

This study is retrospective and examined a consecutive cohort of patients recruited in 2 centers (St-Etienne University Hospital, St-Etienne, France, and Salus Hospital GVM Care \& Research, Reggio Emilia, Italy) between September 2012 and May 2014 who were being evaluated for an implantation with the $3 \mathrm{f}$ Enable sutureless valve via RAMT. Inclusion criteria for RAMT implantation of the valve were presence of a severe aortic valve stenosis, age $>60$ years, and New York Heart Association (NYHA) class III or higher. All candidates for RAMT were explored preoperatively with a thoracic and abdominal computed tomography scan, to detect: presence of heavy calcifications of the ascending aorta, which would contraindicate the RAMT approach; presence of a very short ascending aorta necessitating a retrograde femoral arterial cannulation; and permeability of the iliac arteries and veins.

Exclusion criteria were: an ejection fraction $<30 \%$; recent endocarditis; reoperation; an intraoperative aortic annulus measurement $>25 \mathrm{~mm}$ associated with a bicuspid anatomy; aneurysmal dilatation of the ascending aorta needing surgical correction; any other indication for associated surgical procedures (coronary artery bypass graft, mitral valve surgery); known hypersensitivity to nickel alloys; and nonelective surgery. We selected 71 patients to undergo an aortic valve replacement via RAMT. The internal review board of the 2 institutions allowed treatment of personal data, and patients provided specific written consent.

Data collection from both centers was uniformly performed; included items were preoperative clinical and hemodynamic characteristics, intraoperative and postoperative items, and clinical follow-up and echography data. All recordings were collected in an integrated database. Adverse events were death, stroke, embolism, nonstructural valve dysfunction, hemorrhage, endocarditis, conductive blocks requiring pacemaker implantation, and cardiac decompensation; these were divided into early (within 30 days postoperatively) and late (after 30 days) categories. Clinical neurologic assessment was performed by our cardio-anesthesiologists. Paravalvular leakages (PVLs) were classified as absent (0), trace (< grade I), mild (grade I), moderate (grade II), or severe (grade III or IV). Before discharge, patients underwent transthoracic echocardiography. Echocardiographic examinations were performed with Vivid-7 Dimension ultrasound platforms (GE Healthcare, Milwaukee, Wis).

\section{Follow-up}

Clinical and echocardiographic postimplantation evaluation during follow-up was performed at the cardiologic unit in both centers. Control evaluations were performed between 6 months and 1 year after the operation. Data for NYHA classification were presented as the number and percentage of patients in each functional class. During follow-up, transthoracic echocardiography mean and peak transvalvular gradient, valvular orifice area, and presence of leakages were registered. Event-free survival was defined as the absence of: death, stroke, embolism, nonstructural valve dysfunction, hemorrhage, endocarditis, conductive blocks necessitating pacemaker implantation, cardiac decompensation, and reoperation.

\section{Device Description}

The $3 \mathrm{f}$ Enable valve Figure 1, $A$ ) is composed of 3 equal leaflets of equine pericardial tissue that are sutured to one another, and have been treated with glutaraldehyde to preserve the structure of the collagen matrix. This part of the device derives from the ATS 3F stentless valve (ATS Medical, Lake Forest, CA). That tubular biologic conduit was reinforced with polyester material and included into a self-expanding nitinol frame, covered on the inflow with a polyester flange; as such, it could be rapidly expanded and fixed into the aortic annulus of the receiver without sutures. The inclusion into the nitinol stent confers a symmetric suspension of the commissures, eliminating technical pitfalls linked to surgical resuspension.

\section{Surgical Technique}

Minithoracotomy and exposure. The RAMT management approach adopted is, in brief, the same as that previously proposed by Cerillo and colleagues. ${ }^{11}$ After selective endotracheal ventilation, and under transesophageal echography, a second right minithoracotomy of 5 to $7 \mathrm{~cm}$ right anterior minithoracotomy is performed in the second intercostal space, followed by femoral venous percutaneous cannulation with the Seldinger technique (using a DLP venous cannula, Medtronic, Inc, Minneapolis, Minn). The pericardium is incised and suspended directly from the skin. That maneuver moves the ascending aorta aside, making evaluation easier of whether a direct aortic antegrade cannulation is 

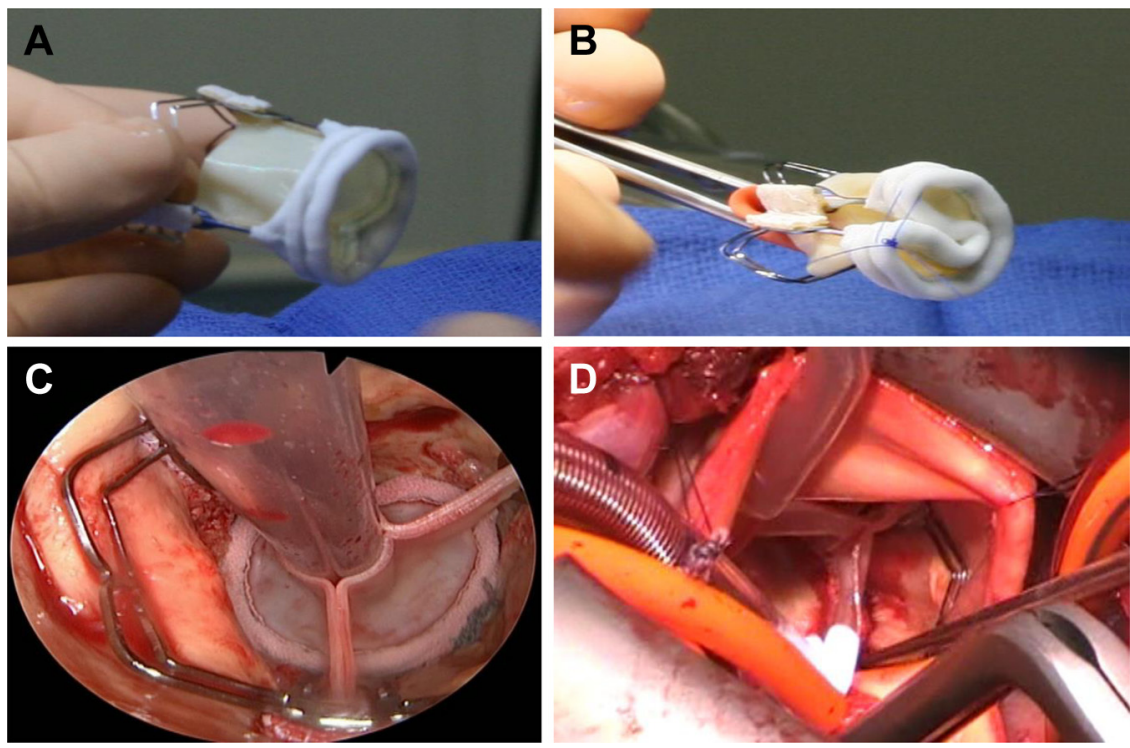

FIGURE 1. A, The $3 \mathrm{f}$ Enable valve (Medtronic, Inc, Minneapolis, Minn) before folding. B, The prosthesis, folded, is kept compressed by a 4-0 polypropylene stitch. C, Valve is deployed with the leaflets collapsing around the suction cannula (vacuum induction into the ventricule). D, Operative field during control of sealing with a nerve hook. Note the antegrade arterial cannulation.

feasible (using the Seldinger technique; Edwards OptiSite arterial cannula, Edwards Lifesciences, Irvine, Calif). In cases in which the ascending aorta is shorter than $5 \mathrm{~cm}$ in the intrapericardial portion, a mini-incision is made in the inguinal groin, to prepare a femoral retrograde arterial perfusion.

The cardiopulmonary bypass (CPB) is started: a vent is inserted into the aortic root; the aorta is cross-clamped (L-shaped DeBakey aortic clamp or Chitwood clamp, the latter positioned with transcutaneous access in the second or first intercostal space); the right superior vein is vented; and an antegrade infusion of crystalloid intracellular cardioprotective solution (histidine-tryptophanketoglutarate cardioplegic solution, Köhler Chemie $\mathrm{GmbH}$, Alsbach-Hahnlein, Germany) is performed for 8 minutes. After these steps, an intrathoracic $\mathrm{CO}_{2}$ inflation is begun (continued throughout the $\mathrm{CPB}$ procedure). Once the cardioplegia is terminated, the aortic vent is ablated, the ascending aorta is transected, and the root is exposed; the dome of the ascending aorta is retracted toward the right pericardium with a stay stitch of 4-0 polypropylene, to liberate the view of the axis of the aortic valve. The ideal decalcification should be performed without completely peeling the annulus and leaving a minimum of material without important irregularities, to assure an optimal grip of the bioprosthesis flange by the receiver tissues.

Sizing. Sizes of the $3 \mathrm{f}$ Enable valve indicate the intra-annular diameter of the device ( $6 \mathrm{~mm}$ undersized compared with the external diameter of the corresponding prosthesis). The size of the valve should be selected as corresponding to a sizer allowing an unforced passage through the annulus.

Positioning and release of the prosthesis. The valve is manually folded, and especially in cases of small roots, a temporary 4-0 polypropylene stitch (compression stitch, Figure 1,B) is placed in the cuff, to prevent any unfolding of the valve before expansion is wanted. A guiding suture is placed in the noncoronary sinus. During the first quarter of such procedures we performed, we positioned this stitch in the nadir (middle) of the noncoronary sinus, but after that, we decided to position it in the left third of the noncoronary sinus (nearer to the mitro-aortic trigon). This approach was adopted to increase the possibility of adjusting the level of placement (and thus of delivery of the radial force) of the Enable flange to correspond with the anatomic location of the atrioventricular conduction tissue and reduce the incidence of blocks.
The stitch is then tied off. The left side of the sutureless prosthesis is kept in contact with the native annulus with a grasper and fixed into position. The compression stitch is cut and removed.

TABLE 1. Preoperative characteristics of the study population $(\mathbf{n}=\mathbf{7 1})$

\begin{tabular}{lcc}
\hline \multicolumn{1}{c}{ Variable } & $\begin{array}{c}\text { Mean } \pm \text { SD } \\
\text { or n (\%) }\end{array}$ & $\begin{array}{c}\text { Median } \\
\text { (min-max) }\end{array}$ \\
\hline Age $(\mathrm{y})$ & $77.4 \pm 5.0$ & $78(63-87)$ \\
Log euroSCORE & $8.1 \pm 5.5$ & $7.0(1.9-24.8)$ \\
BMI $\left(\mathrm{kg} / \mathrm{m}^{2}\right)$ & $26.6 \pm 4.0$ & $26.0(21.0-39.0)$ \\
Left ventricular ejection fraction (\%) & $55 \pm 3$ & $60.0(35-75)$ \\
Preoperative mean transvalvular & $59.1 \pm 14.5$ & $55(39-104)$ \\
$\quad$ gradient (mm Hg) & $39(54.9)$ & - \\
Male gender & $45(63.3)$ & - \\
Hypertension & $20(28.1)$ & - \\
Diabetes & $36(50.7)$ & - \\
Dyslipidemia & $16(22.5)$ & - \\
Obesity (BMI $\left.>30 \mathrm{~kg} / \mathrm{m}^{2}\right)$ & $8(11.2)$ & - \\
Renal insufficiency $(\mathrm{SCr}>2 \mathrm{mg} / \mathrm{dL})$ & $8(11.2)$ & - \\
Chronic lung disease & $2(2.8)$ & - \\
Previous stroke or TIA & $64(90.1)$ & - \\
$\quad$ NYHA class III & $7(9.8)$ & - \\
NYHA class IV & & - \\
Preoperative rhythm & $65(91.5)$ & - \\
Sinusal & $4(5.6)$ & - \\
AF & $2(2.8)$ & \\
Pacemaker & &
\end{tabular}

Diabetes refers to patients under medication. Chronic lung disease refers to patients under long-term medication for chronic bronchitis or emphysema and pathologic pulmonary function test. $S D$, Standard deviation; min, minimum; max, maximum; euroSCORE, European System for Cardiac Operative Risk Evaluation; BMI, body mass index; $S C r$, serum creatinine; TIA, transitory ischemic attack; NYHA, New York Heart Association; $A F$, atrial fibrillation. 
TABLE 2. Perioperative outcomes

\begin{tabular}{|c|c|c|}
\hline Outcome & $\begin{array}{c}\text { Mean } \pm \text { SD } \\
\text { or } n(\%)\end{array}$ & $\begin{array}{l}\text { Median } \\
(\text { min-max })\end{array}$ \\
\hline CPB time (min) & $91 \pm 29$ & $89(48-172)$ \\
\hline Aortic cross-clamp time (min) & $66 \pm 19^{*}$ & $64(37-126)$ \\
\hline \multicolumn{3}{|l|}{ Size of implanted prosthesis (mm) } \\
\hline 19 & $9(12.6)$ & - \\
\hline 21 & $18(25.3)$ & - \\
\hline 23 & $25(35.2)$ & - \\
\hline 25 & $15(21.1)$ & - \\
\hline 27 & $4(5.6)$ & - \\
\hline Reclamping & $4(5.6)$ & - \\
\hline Ventilation time $(\mathrm{h})$ & $10.5 \pm 13.2$ & $9(1-96)$ \\
\hline Surgical revision for bleeding & $1(1.4)$ & - \\
\hline $\begin{array}{l}\text { Bleeding (volume at drainage } \\
\text { removal) }(\mathrm{ml})\end{array}$ & $392 \pm 184$ & $362(150-1070)$ \\
\hline Intensive care unit stay (d) & $2.7 \pm 1.3$ & $2(1-10)$ \\
\hline Respiratory distress & $1(1.4)$ & - \\
\hline New onset of atrial fibrillation & $8(11.2)$ & - \\
\hline Pacemaker implantation & $4(5.6)$ & - \\
\hline 30-d mortality, n (\%) & $2(2.8)$ & - \\
\hline Stroke, n $(\%)$ & $0(0)$ & - \\
\hline TIA, n (\%) & $2(2.8)$ & - \\
\hline
\end{tabular}

Considering the right side of the valve to be "de-folded," the upper part of the stent can be expanded using a grasper with closed jaws before expanding the lower part (cuff). In this way, better visual control of the cuff (annular level) is obtained while it is gently pulled to the right native annulus. Adhesion to the native annulus can be achieved by gently inserting a curved instrument through the leaflets of the bioprosthesis and exerting pressure from inside the cuff toward the outside. Before activating full expansion of the nitinol frame by adding warm saline, sealing of the sutureless valve is checked by induction of a vacuum into the left ventricle (Figure 1,C), and use of a nerve hook (Figure 1,D).

Transesophageal echography control. After weaning from the $\mathrm{CPB}$, accurate transesophageal echography PVL detection is performed. Grade I or greater PVL is not acceptable in our protocol and requires a new cross-clamp. This procedure is started immediately, to reposition or replace the implanted sutureless bioprosthesis.

TABLE 3. Follow-up

\begin{tabular}{lcc}
\hline \multicolumn{1}{c}{ Variable } & Mean \pm SD or n $(\%)$ & Median (min-max) \\
\hline Follow-up duration (mo) & $8.1 \pm 3.5$ & $7(1-16)$ \\
Death & $3 / 71(4.2)$ & - \\
Stroke, n $(\%)$ & $0(0)$ & - \\
TIA & $2(2.8)$ & - \\
Reoperation & $0(0)$ & - \\
Endocarditis & $0(0)$ & - \\
Late pacemaker & $0(0)$ & - \\
$\quad$ implantation & & - \\
NYHA class 1 & $35(49.2)$ & - \\
NYHA class II & $29(40.8)$ & - \\
NYHA class III & $4(5.6)$ & \\
\hline
\end{tabular}

$S D$, Standard deviation; min, minimum; max, maximum; TIA, transitory ischemic attack; NYHA, New York Heart Association.
TABLE 4. Results for 3f Enable hemodynamic parameters

\begin{tabular}{|c|c|c|c|}
\hline Parameter & $\begin{array}{l}\text { Preoperative } \\
\quad(n=71)\end{array}$ & $\begin{array}{c}\text { Discharge } \\
(\mathrm{n}=69)\end{array}$ & $\begin{array}{l}\text { 6-12 Months } \\
(\mathrm{n}=47)\end{array}$ \\
\hline $\begin{array}{l}\text { Mean systolic gradient } \\
(\mathrm{mm} \mathrm{Hg})\end{array}$ & $59.1 \pm 14.0$ & $10.7 \pm 4.3$ & $9.6 \pm 3.1$ \\
\hline $\begin{array}{l}\text { Peak systolic gradient } \\
\text { (mm Hg) }\end{array}$ & $91.1 \pm 20.0$ & $19.0 \pm 9.5$ & $16.2 \pm 4.7$ \\
\hline $\mathrm{EOA}\left(\mathrm{cm}^{2}\right)$ & $0.64 \pm 0.18$ & $1.73 \pm 0.40$ & $1.71 \pm 0.32$ \\
\hline $\begin{array}{l}\text { Intravalvular leakages, } \\
\mathrm{n}(\%)\end{array}$ & - & $1(1.4)$ & $1(1.4)$ \\
\hline No PVL, n (\%) & - & $67(94.3)$ & $60(94.3)$ \\
\hline $\mathrm{PVL}<$ grade $1, \mathrm{n}(\%)$ & - & $3(4.2)$ & $3(4.2)$ \\
\hline $\mathrm{PVL}=$ grade $1, \mathrm{n}(\%)$ & - & $1(1.4)$ & $1(1.4)$ \\
\hline $\mathrm{PVL}>$ grade $1, \mathrm{n}(\%)$ & - & $0(0)$ & $0(0)$ \\
\hline
\end{tabular}

For the intravalvular leakages, the grade of the leakage is 1 , and these involved a size 19-mm prosthesis. EOA, Effective orifice area; $P V L$, paravalvular leakage.

\section{Statistical Analysis}

Demographic, clinical, and operative data are expressed as mean \pm standard deviation, or median and range of minimal and maximal values, as appropriate. Categoric variables are presented as numbers with percentages. Statistical analyses were performed using Statview, version 5.0 (SAS Institute, Inc, Cary, NC).

\section{RESULTS}

Patients' demographics and characteristics are summarized in Table 1. The mean population logistic euroSCORE was $8.1 \pm 5.5$ (median: 7.0, range: 1.9-24.8). Intraoperative data are reported in Table 2. In 1 case, conversion to full sternotomy was necessary before arterial and venous cannulation, because of severe pleural and pericardial adhesions. In $21(29 \%)$ cases, a femoral artery cannulation was needed because the retained ascending aorta was too short for an antitrade cannulation. Intraprocedural success of the valve implantation was $100 \%$, but in 4 cases, a reclamping procedure was necessary after an immediate regurgitation that was judged to be unacceptable ( $\geq$ grade I). Two of these cases were resolved with a simple repositioning of the valve; 2 required implantation of a new, larger valve $(23 \mathrm{~mm}$ instead of $21 \mathrm{~mm}$, and $25 \mathrm{~mm}$ instead of $23 \mathrm{~mm}$, respectively).

The mean and median sizes of the implanted valves were, respectively, $22.6 \pm 2.1 \mathrm{~mm}$, and $23(19-27) \mathrm{mm}$. The mean aortic cross-clamping and mean $\mathrm{CPB}$ times were, respectively, $66 \pm 19$ minutes and $91 \pm 29$ minutes. In 1 case, a grade I PVL was not corrected, owing to comorbidities and the age ( 82 years) of the patient.

No intraprocedural death was registered. Immediate revision for hemostasis was necessary in 1 case. Mean volume before thoracic drainage removal was $392 \pm 184$ $\mathrm{ml}$. Mean ventilation time and intensive care unit stay were, respectively, $10.5 \pm 13.2$ hours, and $2.7 \pm 1.3$ days. During hospitalization, $4(5.6 \%)$ patients required the implantation of a pacemaker. One patient died on 
postoperative day 7 after an acute hypoxia; autopsy eliminated a valve-related etiology of the event. A second patient died suddenly at postoperative day 10 . Autopsy eliminated a pulmonary embolism, hemorrhage, myocardial infarction, and valve dislocation: a malignant arrhythmia could not be excluded, and the event was considered valve related.

The mean clinical and echographic follow-up duration was $8.1 \pm 3.5$ months (median: 7 months; range: 1-16 months). Follow-up clinical results are reported in Table 3. No cases of stroke, embolism, structural valve dysfunction, hemorrhage, endocarditis, or further conductive blocks necessitating pacemaker implantation were registered. One patient died 6 months after surgery (of peritonitis).

At mean follow-up, $35(49.2 \%)$ patients were in NYHA class I, $29(40.8 \%)$ were in class II, and $4(5.6 \%)$ were in class III, with a significant increase of those in NYHA class I and II, compared with the preoperative state $(P<.05)$. Valve hemodynamics are reported in Table 4 . The mean and peak transvalvular gradients were, respectively, $9.2 \pm 3.3 \mathrm{~mm} \mathrm{Hg}$, and $16 \pm 4.7 \mathrm{~mm} \mathrm{Hg}$. The effective orifice area was $1.71 \pm 0.32 \mathrm{~cm}^{2}$ at the $6-12$ month follow-up control. During the follow-up period, no new-onset PVL was detected, and the degree of regurgitation remained stable in all cases. One-year freedom from adverse events, and all-cause and valverelated mortality, was, respectively, $85 \%, 97 \%$, and $99 \%$.

\section{DISCUSSION}

This study evaluated a cohort of 71 patients collected from 2 centers. The team at the first center (in St-Etienne, France) proctored the team at the second center (in Reggio Emilia, Italy), which adopted the same Enable RAMT protocol, considering surgical indications, technique, and cardiac protection, designed to maximize the probability of homogeneity in the cohort. Population analysis showed no differences in preoperative characteristics, including age, risk factors, or body mass index, between the centers.

In both centers, MT sutureless cross-clamping and CPB times were similar to those of full sternotomy procedures performed with conventional bioprostheses, with a cumulative reduction of $35 \%$ compared with the RAMT cross-clamping time (102 \pm 20 minutes), with use of sutured prostheses in a group of 37 patients undergoing operations in the same time period ( 27 men, 10 women; mean age, logistic euroSCORE, and ejection fraction were, respectively, $64 \pm 11$ years, $3.64 \% \pm 1.2 \%$, and $57 \% \pm 12 \%)$. Similar findings have been reported regarding mini-sternotomy access with other sutureless valves. ${ }^{12-14}$ Our results thus confirm the usefulness of the $3 \mathrm{f}$ Enable device in providing increased speed and simplifying the minimally invasive aortic valve replacement procedure.
The sutureless RAMT replacement seemed feasible for both groups, irrespective of the relationships between the ascending aorta and the sternum. This factor has been described by another team ${ }^{11}$ with use of sutured valves via RAMT, ${ }^{11}$ but because the absence of sutures enables greater working distances between the skin and the aortic valve plane, it becomes less restrictive in patient selection. Nevertheless, a computed tomography scan remains mandatory in the pre-evaluation of the patient, to exclude intraoperative discovery of a type 0 bicuspid aortic valve, which would necessitate a change to a sutured bioprosthesis.

The incidence of immediate reclamping (5.6\%) may seem, in our report, to be relatively higher than that in cohorts involving use of other sutureless valves. ${ }^{15}$ These data need to be interpreted with caution, given our aggressive policy regarding immediate detection of PVL via transesophageal echography: We did not accept grade I leakages, except in 1 frail, octogenarian patient, and we proceeded with their systematic correction. At both centers, the initial experience with RAMT implantation for sutureless valves was as follows: In 4 cases, reclamping was necessary ( 2 at the first center, and 2 at the second center). Two of those 4 patients needed implantation of a larger bioprosthesis, a fact that could be attributable to a hypothetic higher risk of undersizing of the aortic annulus during the RAMT approach compared with sternotomy. Nevertheless, a learning curve effect cannot be excluded, because these patients were among the first quarter of those treated with the sutureless device using RAMT in this experience at multiple centers.

The $3 \mathrm{f}$ Enable valve is the only sutureless CE (European conformity)-marked device that is not balloon expandable (as opposed to the Perceval S [Sorin Biomedica Cardio Srl, Saluggia, Italy] and Edwards Intuity [Edwards Lifesciences, Irvine, Calif]) and requires a pure surgical method to expand and position the polyester cuff at the proper level of the native aortic annulus. After knotting the guiding stitch in the nadir of the noncoronary segment of the native annulus, during the expansion of the nitinol frame, the remaining portion of the cuff must not be blocked using further stitches. That supplemental fixation would impair the free redistribution of the radial force of the nitinol frame during expansion of the collapsed leaflet, tending to produce portions of unsealing between the valve and the patient annulus.

Learning the precise sequence of the step-by-step delivery of the $3 \mathrm{f}$ Enable valve, as previously described, may be more difficult than learning techniques with sutureless, balloon expandable devices, which do not require surgical manipulations into the aortic root and are based exclusively on sizing. The positioning sequence has to be completely achieved during sternotomy or mini-sternotomy before a switch to RAMT is made. Conversely, compared with the 
Perceval S and Intuity bioprostheses, the $3 \mathrm{f}$ Enable valve can be easily repositioned, in cases of initial unsatisfactory positioning, to obtain perfect placement of the device into the native annulus. In addition, in our experience, the valve has excellent midterm stability in the aortic root, a relatively low incidence of nontrivial PVL, no migration, and no newonset PVL during follow-up.

Conductive blocks requiring pacemaker implantation were, in our experience, $5.6 \%$, which compares favorably with the initial experience of Eichstaedt and colleagues, ${ }^{16}$ but conversely, that percentage is higher than that found in other cohorts treated with sutureless devices. ${ }^{14}$ These conductive blocks occurred during the first quarter of procedures during our experience; after that point, the incidence of such complications was $0 \%$, apparently showing an effective evolution of our positioning technique.

The hemodynamic data are encouraging, consistent with previous reports on the $3 \mathrm{f}$ Enable valve, ${ }^{17,18}$ and associated with significant clinical amelioration. These results confirm the potential indication of using such sutureless valves in other subgroups of patients, such as those with small annuli. A study evaluating the regression of the ventricular mass in these subsets would be of interest.

The satisfactory 5-year durability of the $3 \mathrm{f}$ Enable valve, ${ }^{18}$ and the encouraging initial experience via the RAMT approach with this sutureless bioprosthesis, should boost the increasing adoption of such settings in the future as a first-line method of biologic aortic valve replacement.

\section{Study Limitations}

Our study is a retrospective analysis of a consecutive cohort of patients from 2 centers. During follow-up, we could not obtain systematic transthoracic echocardiography at 6 and 12 months, but we did obtain a unique control between 6 and 12 months.

\section{CONCLUSIONS}

The RAMT aortic valve replacement procedure with the sutureless $3 \mathrm{f}$ Enable valve is safe and reproducible and offers satisfactory results in terms of limited operative times, despite a necessary learning curve. The incidence of PVL and the transvalvular gradients are interestingly low. Larger studies are needed to compare the benefits of the $3 \mathrm{f}$ Enable sutureless prosthesis with those of other CE-marked sutureless prostheses in the RAMT aortic valve replacement approach.

\section{Conflict of Interest Statement}

Marco Vola and Alberto Albertini report consulting and lecture fees from Medtronic (Medtronic, Inc, Minneapolis,
Minn). Jean-Francois Fuzellier reports lecture fees from Medtronic. All other authors have nothing to disclose with regard to commercial support.

\section{References}

1. Adams DH, Popma JJ, Reardon MJ, Yakubov SJ, Coselli JS, Deeb GM, et al. Transcatheter aortic-valve replacement with a self-expanding prosthesis N Engl J Med. 2014;370:1790-8.

2. Seiffert M, Conradi L, Kloth B, Koschyk D, Schirmer J, Schnabel RB, et al. Single-centre experience with next-generation devices for transapical aortic valve implantation. Eur J Cardiothorac Surg. 2015;47:39-45.

3. Fanning JP, Wesley AJ, Platts DG, Walters DL, Eeles EM, Seco M, et al. The silent and apparent neurological injury in transcatheter aortic valve implantation study (SANITY): concept, design and rationale. BMC Cardiovasc Disord. 2014;14:45.

4. Dogan S, Dzemali O, Wimmer-Greinecker G, Derra P, Doss M, Khan MF, et al. Minimally invasive versus conventional aortic valve replacement: a prospective randomized trial. J Heart Valve Dis. 2003;12:76-80.

5. Cohn LH, Adams DH, Couper GS, Bichell DP. Minimally invasive aortic valve replacement. Semin Thorac Cardiovasc Surg. 1997;9:331-6.

6. Vola M, Fuzellier JF, Chavent B, Duprey A. First human totally endoscopic aortic valve replacement: an early report. J Thorac Cardiovasc Surg. 2014; 147:1091-3.

7. Glauber M, Miceli A, Gilmanov D, Ferrarini M, Bevilacqua S, Farneti PA, et al. Right anterior minithoracotomy versus conventional aortic valve replacement: a propensity score matched study. J Thorac Cardiovasc Surg. 2013;145:1222-6.

8. Brinkman WT, Hoffman W, Dewey TM, Culica D, Prince SL, Herbert MA, et al. Aortic valve replacement surgery: comparison of outcomes in matched sternotomy and PORT ACCESS groups. Ann Thorac Surg. 2010; 90:131-5.

9. Miceli A, Murzi M, Gilmanov D, Fuga R, Ferrarini M, Solinas M, et al Minimally invasive aortic valve replacement using right minithoracotomy is associated with better outcomes than ministernotomy. J Thorac Cardiovasc Surg. 2014;148:133-7.

10. Gilmanov D, Farneti PA, Miceli A, Bevilacqua S, Glauber M. Perceval S sutureless aortic valve prosthesis implantation via a right anterior minithoracotomy. Multimed Man Cardiothorac Surg. 2013;2013:mmt012.

11. Cerillo AG, Bevilacqua S, Farneti PA, Concistre G, Glauber M. Sutureless aortic valve replacement through a right minithoracotomy. J Heart Valve Dis. 2012;21: 168-71.

12. Santarpino G, Pfeiffer S, Concistre G, Grossmann I, Hinzmann M, Fischlein T The Perceval S aortic valve has the potential of shortening surgical time: Does it also result in improved outcome? Ann Thorac Surg. 2013;96:77-82.

13. Santarpino G, Pfeiffer S, Concistre G, Fischlein T. Perceval S aortic valve implantation in mini-invasive surgery: the simple sutureless solution. Interact Cardiovasc Thorac Surg. 2012;15:357-60.

14. Miceli A, Santarpino G, Pfeiffer S, Murzi M, Gilmanov D, Concistre G, et al Minimally invasive aortic valve replacement with Perceval S sutureless valve: early outcomes and one-year survival from two European centers. J Thorac Cardiovasc Surg. 2014;148:2838-43.

15. Gilmanov D, Miceli A, Bevilacqua S, Farneti P, Solinas M, Ferrarini M, et al. Sutureless implantation of the Perceval S aortic valve prosthesis through right anterior minithoracotomy. Ann Thorac Surg. 2013;96:2101-8.

16. Eichstaedt HC, Easo J, Harle T, Dapunt OE. Early single-center experience in sutureless aortic valve implantation in 120 patients. J Thorac Cardiovasc Surg. 2013;147:370-5.

17. Aymard T, Kadner A, Walpoth N, Gober V, Englberger L, Stalder M, et al. Clinical experience with the second-generation 3f Enable sutureless aortic valve prosthesis. J Thorac Cardiovasc Surg. 2010;140:313-6.

18. Englberger L, Carrel TP, Doss M, Sadowski J, Bartus K, Eckstein FF, et al Clinical performance of a sutureless aortic bioprosthesis: five-year results of the 3f Enable long-term follow-up study. J Thorac Cardiovasc Surg. 2014;148: $1681-7$. 